\title{
KAJIAN PENERAPAN PRINSIP WATER CONSERVATION SESUAI STANDAR GREENSHIP NEW BUILDING VERSI 1.2 STUDI KASUS: GEDUNG P1 DAN P2 UNIVERSITAS KRISTEN PETRA SURABAYA
}

\author{
Steviani Dewi Teddy ${ }^{1}$, Jimmy Priatman², dan Nugroho Susilo ${ }^{3}$
}

\begin{abstract}
ABSTRAK : Isu green building dewasa ini menjadi sangat penting untuk diterapkan. Alasan utamanya adalah karena bangunan mengkonsumsi begitu banyak sumber daya alam, di tengah-tengah krisis energi dan air yang sedang melanda dunia. Penelitian ini dimaksudkan untuk mengetahui seberapa besar penghematan air yang dapat dicapai oleh gedung P1 dan P2 dengan menerapkan konsep penggunaan fitur hemat air, rainwater harvesting, serta daur ulang grey water. Penghematan ini berkaitan dengan jumlah poin yang berpotensi diperoleh gedung P1 dan P2 untuk credit WAC 1 sampai dengan WAC 6 menurut Greenship New Building Versi 1.2.
\end{abstract}

Untuk memprediksi penggunaan air di gedung $\mathrm{P} 1$ dan $\mathrm{P} 2$, dilaksanakan survei melalui kuesioner. Pengguna gedung $\mathrm{P}, \mathrm{W}$, dan T Universitas Kristen Petra Surabaya dipilih secara acak sebagai responden. Dari hasil kajian, desain asli gedung P1 dan P2 berpotensi memperoleh 17 poin untuk kategori water conservation dari total 20 poin. Usulan-usulan diberikan untuk menyempurnakan desain gedung P1 dan P2 sehingga bisa mencapai perolehan 20 poin maksimum.

Kata Kunci:

water conservation, fitur hemat air, rainwater harvesting, daur ulang grey water.

ABSTRACT : Nowadays, green building issue has become very important. The main reason is that buildings consume much of natural resources, in the middle of world energy and water crisis which is happening around the world. The goal of this research is to find out how much water saving that $P 1$ and $P 2$ building can achieve by applying the concepts of water saving fixture usage, rainwater harvesting, and grey water recycling. This saving is related to how many points that bulding can potentially achieve for WAC 1 to WAC 6 credit according to Greenship for New Building version 1.2 standard.

To predict water consumption at $P 1$ and $P 2$ buildings, a questionnaire survey was conducted. Occupants of $P, W$, and $T$ buildings of Petra Christian University Surabaya were randomly chosen as respondents. As the result of this research, $P 1$ and $P 2$ building original design is potential to achieve 17 points out of total 20 points. Suggestions are proposed to perfect the design of $P 1$ and $P 2$ building in order to achieve maximum 20 points.

Keywords:

Water conservation, efficient water fixture, rainwater harvesting, grey water recycling.

\footnotetext{
${ }^{1}$ Mahasiswa Program Studi Magister Teknik Sipil Universitas Kristen Petra, steviani@hotmail.com

${ }^{2}$ Dosen Program Studi Magister Teknik Sipil Universitas Kristen Petra, ipriatman@yahoo.com

${ }^{3}$ Dosen Program Studi Magister Teknik Sipil Universitas Kristen Petra, nugroho@mitra.net.id
} 


\section{PENDAHULUAN}

Pada awal perkembangannya, Green Building dianggap sebagai suatu aspek "kemewahan" pada bangunan, sehingga penerapannya pun tidak dianggap penting/mutlak untuk dilakukan. Oleh karena itu, dahulu, pemilik gedung yang tertarik untuk menerapkan konsep "green" sangatlah terbatas jumlahnya. Namun seiring dengan perkembangan zaman, masyarakat modern mulai menyadari pentingnya konsep Green Building untuk diterapkan. Konsep Green Building tidak lagi dianggap hanya sebagai sebuah fashion statement, melainkan sebuah kebutuhan karena banyak manfaat yang bisa diperoleh melalui penerapannya. Mengapa isu Green Building menjadi begitu penting untuk diterapkan? Alasan utamanya adalah karena bangunan gedung mengkonsumsi begitu banyak sumber daya alam, di tengah-tengah krisis energi dan air yang sedang melanda dunia. Fakta ini mendorong ide para desainer untuk kembali mendesain bangunan yang diselaraskan dengan alam.

Green Building Council Indonesia (GBCl) merupakan sebuah lembaga independen yang mendedikasikan diri sebagai penilai penerapan Green Building khusus di wilayah Indonesia, serta memberikan sertifikasi Greenship bagi bangunan yang memenuhi standar penilaian mereka. Ada 6 aspek Green Building yang menjadi pedoman $\mathrm{GBCl}$ untuk memberikan penilaian tingkat "kehijauan" suatu bangunan di Indonesia, yaitu:

1. Appropriate Site Development/ASD

2. Energy Efficiency and Conservation

3. Water Conservation

4. Material Resource and Cycle

5. Indoor Health and Comfort

6. Building Environmental Management

Jika dibandingkan dengan keempat aspek penilaian Green Building lainnya, aspek water conservation dan energy efficiency memiliki bobot yang paling besar dengan masing-masing nilai $27 \%$ poin dan $34 \%$ poin untuk tahap Design Recognition. Namun, dipilih khusus aspek water conservation untuk dikaji lebih mendalam dalam penelitian ini, karena untuk aspek energy efficiency sudah pernah diteliti sebelumnya di dalam penelitian terdahulu.

\subsection{Perumusan Masalah}

1. Berapa persen penghematan air dan poin untuk credit WAC yang dapat dicapai oleh desain gedung P1 dan P2 menurut standar Greenship NB versi 1.2?

2. Langkah optimasi apa yang bisa dilakukan agar gedung $P 1$ dan $P 2$ bisa memperoleh 20 poin maksimum untuk credit WAC menurut standar Greenship NB versi 1.2?

\subsection{Tujuan Penelitian}

1. Menumbuhkan kesadaran masyarakat, baik kalangan investor, masyarakat konstruksi, maupun praktisi pendidikan, untuk tetap memperhatikan kualitas lingkungan dalam melakukan kegiatan pembangunan/pengembangan lahan, melalui penerapan aspekaspek Green Building, terutama aspek water conservation.

2. Mengoptimalkan perolehan poin di dalam aspek penilaian water conservation tersebut pada desain gedung P1 dan P2 agar bisa menjadi gedung yang hemat air dan mendapat sertifikasi Greenship (sesuai standar GBCl).

3. Memperluas wawasan terhadap penerapan Green Building di Indonesia, khususnya di Surabaya.

\section{LANDASAN TEORI}

\subsection{Konsep Green Architecture dan Green Building}

Arsitektur hijau (Green Architecture) adalah suatu pendekatan perencanaan bangunan yang berusaha untuk meminimalkan berbagai pengaruh membahayakan pada kesehatan manusia 
dan lingkungan (Joga, 2011). Tujuan utama dari green architecture adalah menciptakan ecodesign, arsitektur ramah lingkungan, arsitektur alami, dan pembangunan berkelanjutan. Arsitektur hijau juga dapat diterapkan dengan meningkatkan efisiensi pemakaian energi, air dan pemakaian bahan-bahan yang mereduksi dampak bangunan terhadap kesehatan. Konsep ini sekarang mulai dikembangkan oleh berbagai pihak menjadi Bangunan Hijau (Green Building). Menurut Kim dkk (2000) pada dasarnya Green Building menerapkan prinsipprinsip desain berkelanjutan (sustainable design) dalam konteks rancangan meliputi penghematan sumber daya alam (economy resources), perancangan selama daur hidup (life cycle design), dan rancangan yang manusiawi (human design). Berangkat dari filosofi sustainable design, Green Building adalah konsep bangunan yang fokus pada penghematan lahan, material, energi, air, kualitas udara dan manajemen pengelolaan limbah.

\subsection{Standar Penilaian GBCl untuk Bangunan Baru Versi 1.2}

Suatu bangunan dikatakan sebagai bangunan hijau jika bangunan tersebut telah mendapatkan sertifikat dari lembaga yang ditunjuk (dalam hal ini adalah Green Building Council Indonesia atau GBCI). Adapun perincian tolok ukur yang ditetapkan oleh $\mathrm{GBCl}$ untuk menilai penerapan aspek water conservation ditunjukkan dalam Tabel 1 berikut ini.

Tabel 1. Tolok Ukur Penilaian Aspek Water Conservation dalam Standar GBCI untuk Bangunan Baru Versi 1.2

\begin{tabular}{|c|c|c|c|c|}
\hline \multicolumn{4}{|c|}{ Water Conservation } & \multirow{2}{*}{$\begin{array}{l}\mathbf{2 1 \%} \\
\text { Total } \\
\text { Poin }\end{array}$} \\
\hline Kode & \multicolumn{2}{|l|}{ Keterangan } & Poin & \\
\hline \multirow{3}{*}{ WAC 1} & \multicolumn{2}{|c|}{ Pengurangan Penggunaan Air } & & \\
\hline & \multicolumn{2}{|c|}{$\begin{array}{l}\text { 1. Konsumsi air bersih dengan jumlah tertinggi } 80 \% \text { dari sumber } \\
\text { primer tanpa mengurangi jumlah kebutuhan per orang sesuai } \\
\text { dengan SNI 03-7065-2005 seperti pada tabel terlampir. }\end{array}$} & 1 & \\
\hline & \multicolumn{2}{|c|}{$\begin{array}{l}\text { 2. Setiap penurunan konsumsi air bersih dari sumber primer } \\
\text { sebesar } 5 \% \text { sesuai dengan acuan pada poin } 1 \text { akan mendapat } \\
\text { nilai } 1 \text { dengan nilai maksimum sebesar } 7 \text { poin. }\end{array}$} & $\begin{array}{c}1 \text { s.d. } \\
7\end{array}$ & 8 \\
\hline \multirow{7}{*}{ WAC 2} & \multicolumn{2}{|c|}{ Fitur Air } & & \\
\hline & \multicolumn{2}{|c|}{$\begin{array}{l}\text { 1A. Penggunaan fitur air yang sesuai dengan kapasitas buangan } \\
\text { di bawah standar maksimum kemampuan alat keluaran air } \\
\text { sesuai dengan lampiran, sejumlah minimal } 25 \% \text { dari total } \\
\text { pengadaan produk fitur air. }\end{array}$} & 1 & \multirow{5}{*}{3} \\
\hline & \multicolumn{2}{|l|}{ atau } & & \\
\hline & \multicolumn{2}{|c|}{$\begin{array}{l}\text { 1B. Penggunaan fitur air yang sesuai dengan kapasitas buangan } \\
\text { di bawah standar maksimum kemampuan alat keluaran air } \\
\text { sesuai dengan lampiran, sejumlah minimal } 50 \% \text { dari total } \\
\text { pengadaan produk fitur air. }\end{array}$} & 2 & \\
\hline & \multicolumn{2}{|r|}{ 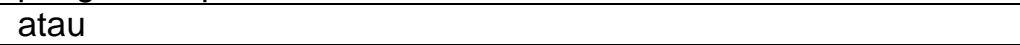 } & & \\
\hline & \multicolumn{2}{|c|}{$\begin{array}{l}\text { 1C. Penggunaan fitur air yang sesuai dengan kapasitas buangan } \\
\text { di bawah standar maksimum kemampuan alat keluaran air } \\
\text { sesuai dengan lampiran, sejumlah minimal } 75 \% \text { dari total } \\
\text { pengadaan produk fitur air. }\end{array}$} & 3 & \\
\hline & $\begin{array}{l}\text { Alat Keluaran Air } \\
\text { WC Flush Valve } \\
\text { WC Flush Tank } \\
\text { Urinal Flush Valve } \\
\text { Keran } \\
\text { Wastafel/Lavatory } \\
\text { Keran Tembok } \\
\text { Shower }\end{array}$ & $\begin{array}{l}\text { Kapasitas Keluaran Air } \\
<6 \text { liter/flush } \\
<6 \text { liter/flush } \\
<4 \text { liter/flush } \\
<8 \text { liter/flush } \\
<8 \text { liter/flush } \\
<9 \text { liter/flush }\end{array}$ & & \\
\hline
\end{tabular}


Tabel 1. Tolok Ukur Penilaian Aspek Water Conservation dalam Standar GBCI untuk Bangunan Baru Versi 1.2 (Sambungan)

\begin{tabular}{|c|c|c|c|}
\hline \multicolumn{3}{|c|}{ Water Conservation } & \multirow{2}{*}{$\begin{array}{l}\mathbf{2 1 \%} \\
\text { Total } \\
\text { Poin }\end{array}$} \\
\hline Kode & Keterangan & Poin & \\
\hline \multirow[t]{4}{*}{ WAC 3} & Daur Ulang Air & & \\
\hline & $\begin{array}{l}\text { 1A. Penggunaan seluruh air bekas pakai (grey water) yang telah } \\
\text { didaur ulang untuk kebutuhan sistem flushing atau cooling tower. }\end{array}$ & 2 & 3 \\
\hline & $\begin{array}{l}\text { 1B. Penggunaan seluruh air bekas pakai (grey water) yang telah } \\
\text { didaur ulang untuk kebutuhan sistem flushing dan cooling tower } \\
-3 \text { nilai }\end{array}$ & 3 & \\
\hline & $\begin{array}{l}\text { Apabila menggunakan sistem pendingin non water cooled, maka } \\
\text { kriteria ini menjadi tidak berlaku sehingga total nilai menjadi } 100 .\end{array}$ & & \\
\hline \multirow[t]{5}{*}{ WAC 4} & Alternative Water Resource & & \\
\hline & $\begin{array}{l}\text { 1A. Menggunakan salah satu dari tiga alternatif sebagai berikut: } \\
\text { air kondensasi } A C \text {, air bekas wudu, atau air hujan. }\end{array}$ & 1 & 2 \\
\hline & $\begin{array}{l}\text { 1B. Menggunakan lebih dari satu sumber air dari ketiga alternatif } \\
\text { di atas }\end{array}$ & 2 & \\
\hline & atau & & \\
\hline & $\begin{array}{l}\text { 1C. Menggunakan teknologi yang memanfaatkan air laut atau air } \\
\text { danau atau air sungai untuk keperluan air bersih sebagai sanitasi, } \\
\text { irigasi, dan kebutuhan lainnya. }\end{array}$ & 2 & \\
\hline \multirow[t]{6}{*}{ WAC 5} & Penampungan Air Hujan & & \\
\hline & $\begin{array}{l}\text { 1A. Menyediakan instalasi tangki penyimpanan air hujan } \\
\text { kapasitas } 50 \% \text { dari jumlah air hujan yang jatuh di atas atap } \\
\text { bangunan yang dihitung menggunakan nilai intensitas curah } \\
\text { hujan harian rata-rata } 10 \text { tahunan. }\end{array}$ & 1 & 3 \\
\hline & atau & & \\
\hline & $\begin{array}{l}\text { 1B. Instalasi tangki penyimpanan air hujan berkapasitas } 75 \% \text { dari } \\
\text { perhitungan di atas }\end{array}$ & 2 & \\
\hline & atau & & \\
\hline & $\begin{array}{l}\text { 1C. Instalasi tangki penyimpanan air hujan berkapasitas } 100 \% \\
\text { dari perhitungan di atas }\end{array}$ & 3 & \\
\hline \multirow[t]{4}{*}{ WAC 6} & Efisiensi Penggunaan Air Lansekap & & \\
\hline & $\begin{array}{l}\text { 1. Seluruh air yang digunakan untuk irigasi gedung tidak berasal } \\
\text { dari sumber air tanah dan/atau PDAM. }\end{array}$ & 1 & 2 \\
\hline & $\begin{array}{l}\text { 2. Menerapkan teknologi yang inovatif untuk irigasi yang dapat } \\
\text { mengontrol kebutuhan air untuk lansekap yang tepat, sesuai } \\
\text { dengan kebutuhan tanaman. }\end{array}$ & 1 & \\
\hline & SUB TOTAL & & 21 \\
\hline
\end{tabular}




\section{METODOLOGI PENELITIAN}

Prosedur yang ditempuh dalam penelitian ini ditunjukkan melalui Gambar 1 berikut:

Belum optimum

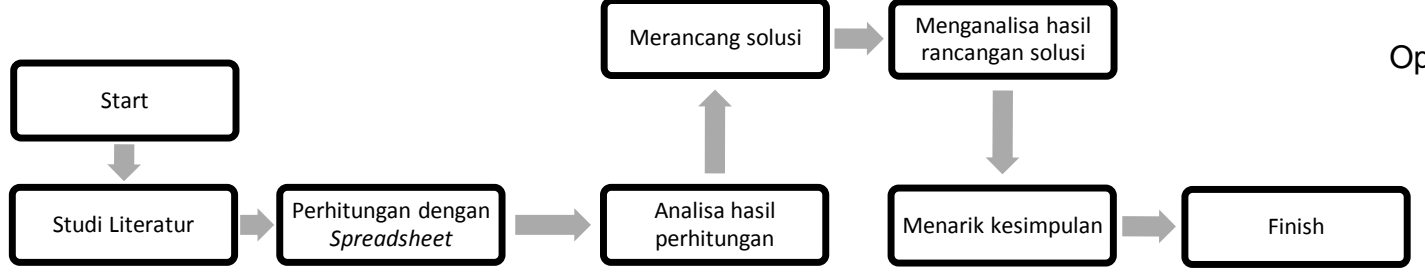

Gambar 1. Diagram Alir Prosedur Penelitian

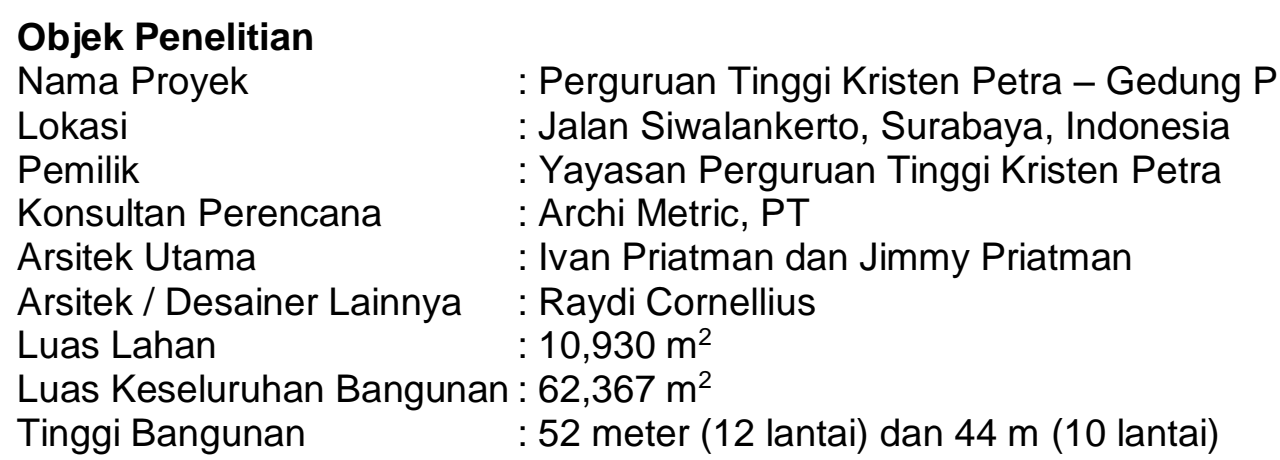

\section{HASIL PENELITIAN DAN PEMBAHASAN}

Untuk memprediksi karakteristik penggunaan air oleh mahasiswa/dosen/staf di Gedung P1 dan P2 Universitas Kristen Petra Surabaya, pada penelitian ini dilakukan survei dengan menyebarkan kuesioner kepada mahasiswa/dosen/staf di gedung $\mathrm{P}, \mathrm{W}$, dan $\mathrm{T}$ Universitas Kristen Petra Surabaya. Dari hasil survei diperoleh nilai rata-rata frekuensi penggunaan masing-masing fitur air oleh mahasiswa/dosen/staf. Nilai ini digunakan untuk memprediksi penggunaan air gedung P1 dan P2. Berikut rincian potensi perolehan 17 poin oleh desain gedung P1 dan P2 dalam kategori WAC:

1. WAC 1 : Pengurangan penggunaan air

Jika dibandingkan dengan standar SNI 03-7065-2005, penggunaan air desain dapat mencapai penghematan 60,38\%. Sehingga untuk kredit WAC 1, gedung P1 dan P2 berpotensi memperoleh 8 poin untuk penghematan airnya.

2. WAC 2 : Penggunaan fitur hemat air

Dengan menggunakan shower, jet shower, dan kran wastafel yang dikategorikan hemat air, berarti $56 \%$ dari jumlah total fitur air yang akan dipasang di gedung P1 dan P2 adalah fitur hemat air dan berpotensi memperoleh 2 poin untuk kredit WAC 2.

3. WAC 3 : Daur ulang air

Seluruh air bekas pakai (grey water) yang telah didaur ulang dimanfaatkan untuk kebutuhan sistem flushing. Maka gedung berhak mendapatkan poin sebesar 2 poin.

4. WAC 4 : Alternative water resource

Dalam perencanaan, gedung P1 dan P2 hanya memanfaatkan sumber air alternatif yang berasal dari air hujan. Oleh karena itu untuk credit WAC 4, Gedung P1 dan P2 hanya berpotensi memperoleh 1 poin.

5. WAC 5 : Penampungan air hujan

Sistem penampungan air hujan disediakan oleh perencana berupa tangki beton berukuran 8 $\mathrm{m} \times 16 \mathrm{~m} \times 2,5 \mathrm{~m}$. Dengan demikian, untuk credit WAC 5, gedung P1 dan P2 berpotensi memperoleh 3 poin dengan menyediakan instalasi tangki dengan kapasitas lebih dari $100 \%$ jumlah air hujan yang jatuh di atas atap bangunan. 
6. WAC 6 : Efisiensi penggunaan air lansekap

Jumlah volume air hujan yang berpotensi untuk ditampung adalah sebanyak $41 \mathrm{~m}^{3} / \mathrm{hari}$, sedangkan kebutuhan irigasi lansekap adalah $30 \mathrm{~m}^{3} /$ hari. Sehingga seluruh air yang digunakan untuk irigasi gedung bisa memanfaatkan air hujan dan tidak berasal dari sumber air tanah dan/atau PDAM. Oleh karena itu, gedung P1 dan P2 berpotensi memperoleh 1 poin untuk kategori efisiensi penggunaan air lansekap.

Untuk memaksimalkan perolehan poin pada kategori WAC (20 poin), diusulkan:

\subsection{Potensi Penambahan Poin untuk WAC 2}

Untuk memperoleh 3 poin, yang merupakan poin penuh untuk kredit WAC 2, minimum 75\% fitur air yang digunakan harus hemat air. Usulan tipe fitur urionir dan kloset hemat air yang bisa diterapkan ditunjukkan dalam Tabel 2.

Tabel 2. Konsumsi Air Fitur Air Usulan

\begin{tabular}{|c|c|c|c|c|c|}
\hline Jenis Fitur Air & Tipe Fitur & Kor & umsi Air Fitur & Keterangan & Penghematan \\
\hline Urinoir katup gelontor & $\begin{array}{l}\text { TOTO } \\
\text { UW350HJT1M }\end{array}$ & 2,5 & liter / flush & Sensor & $37,50 \%$ \\
\hline Kloset tangki gelontor & TOTO C 661JT1 & $6 / 3$ & liter / flush & Dual flush & $40,00 \%$ \\
\hline
\end{tabular}

Kelebihan dari kloset dual flush apabila digunakan dengan tepat akan menghemat konsumsi air, karena jika tidak terdapat buangan padat, volume air yang dibutuhkan untuk penggelontoran hanya separuh dari volume air yang dibutuhkan apabila terdapat buangan padat. Sedangkan kekurangan kloset dual flush antara lain adalah investasi awal yang lebih besar dan apabila tidak digunakan dengan tepat, kloset dual flush tetap memerlukan double flush (contohnya: menggunakan fitur penggelontoran untuk buangan cair padahal terdapat buangan padat).

\subsection{Potensi Penambahan Poin untuk WAC 4}

Gedung P1 dan P2 didesain menggunakan sistem AC VRV (Variable Refrigerant Volume). Oleh karena itu, sumber air alternatif yang berasal dari air kondensasi AC bisa dimanfaatkan. Untuk memperkirakan seberapa banyak air kondensasi yang dapat dihasilkan oleh AC di gedung P1 dan P2, digunakan bantuan web spreadsheet yang dibuat oleh Eddie Wilcut and Elliott Fry dari San Antonio Water System (http://buildinggreen.com). Dari hasil web spreadsheet dengan input antara lain temperatur dan kelembaban udara luar dan indoor, banyaknya air kondensasi AC yang dapat dihasilkan gedung P1 dan P2 adalah 546,49 galon/jam atau 2,068 $\mathrm{m}^{3} / \mathrm{jam}$. Sesuai penelitian Wijaya dkk. (2013) tentang Optimasi Pencahayaan dan Penghawaan Pada Gedung Universitas Kristen Petra (P1\&P2), penghawaan dengan bantuan AC digunakan dari jam 09.00-17.00 (8 jam). Sehingga selama 8 jam penghawaan gedung P1 dan P2 menggunakan AC, dapat dihasilkan 16,5 $\mathrm{m}^{3} / \mathrm{hari}$ air kondensasi yang dapat digunakan untuk kebutuhan flushing dan irigasi lansekap.

\subsection{Potensi Penambahan Poin untuk WAC 6}

Untuk menambah perolehan 1 poin tambahan pada kategori WAC 6, usulan yang dapat diterapkan adalah dengan mengadopsi teknologi irigasi inovatif yang hemat air, contohnya adalah produk Rain Bird. Untuk irigasi lansekap gedung P1 dan P2 diusulkan menggunakan sistem automatic controller sprinkler dengan teknologi modular sprinkler timer. Alat ini akan mengatur buka tutupnya kran air sesuai dengan jadwal dan durasi penyiraman yang kita tentukan. Menggunakan alat multi program ini, area-area lansekap dengan kebutuhan air yang berbeda juga bisa diakomodasi (misal untuk area yang mendapatkan penyinaran matahari lebih banyak butuh lebih banyak air, dan sebaliknya). 


\section{KESIMPULAN DAN SARAN}

\subsection{Kesimpulan}

1. Perencana gedung P1 dan P2 Universitas Kristen Petra Surabaya telah mempertimbangkan aspek-aspek water conservation dan mengintegrasikan aspek-aspek tersebut di dalam desain.

2. Total persentase penghematan air dengan menerapkan $56 \%$ fitur hemat air dan daur ulang greywater adalah $71,3 \%$.

3. Total poin yang berpotensi dicapai oleh Gedung P1 dan P2 (sesuai desain) ini adalah sebesar 17 poin dari total 20 poin untuk kredit WAC 1-6 sesuai penilaian Greenship untuk Bangunan Baru Versi 1.2.

4. Total poin yang berpotensi dicapai oleh gedung P1 dan P2 adalah 20 poin, jika menerapkan usulan-usulan penggunaan kloset hemat air, pemanfaatan air hasil kondensasi $\mathrm{AC}$, dan penggunaan teknologi lansekap inovatif yang hemat air.

5. Dari pengujian faktor-faktor yang diduga berpengaruh terhadap karakteristik penggunaan air, baik oleh mahasiswa maupun dosen dan staf non-akademik, disimpulkan bahwa faktor-faktor tersebut tidak berkorelasi terhadap karakteristik penggunaan air. Oleh karena itu, hasil kajian terhadap potensi poin yang dapat dicapai tidak terpengaruh oleh faktorfaktor perilaku pengguna air dan dapat dinyatakan valid.

\subsection{Saran}

1. Diusulkan pemanfaatan air hasil kondensasi $A C$ sebagai sumber air alternatif yang dapat menambah perolehan 1 poin untuk kategori WAC 4 dan menambah penghematan air menjadi $80,34 \%$.

2. Diusulkan penggunaan kloset dual flush dengan keluaran air $3 \mathrm{~L} / 6 \mathrm{~L}$ untuk menambah perolehan 1 poin pada kategori WAC 2.

3. Sistem irigasi yang dilakukan secara manual diusulkan digantikan secara otomatis dengan menggunakan automatic controller dengan teknologi modular sprinkler timer yang bisa menghemat $10 \%$ penggunaan air, sehingga untuk kategori WAC 6 , gedung bisa menambah perolehan 1 poin.

4. Apabila selama masa operasional gedung, karena faktor pemakaian atau usia fitur air menyebabkan fitur perlu diganti, perlu diperhatikan bahwa spesifikasi fitur pengganti minimal sama atau lebih hemat air. Hal ini bertujuan menghindari penurunan poin pada penilaian water conservation yang sudah dicapai.

5. Keberhasilan penghematan air sesuai dengan desain sangat tergantung pada operasional gedung yang dijalankan oleh manajemen Gedung P1 dan P2. Apabila pemeliharaan terhadap peralatan maupun sistem plambing dilakukan dengan baik dan rutin, maka perolehan poin untuk credit water conservation akan dapat dipertahankan. Sebaliknya, jika tidak dilakukan pemeliharaan dan operasional yang baik, maka sewaktu-waktu perolehan poin bisa mengalami penurunan. Berikut beberapa usulan yang bisa diterapkan oleh manajemen pengelola Gedung P1 dan P2 terkait pengematan air:

- Memberikan sosialisasi kepada mahasiswa, dosen, dan staf non-akademik tentang pentingnya penghematan air. Menumbuhkan kesadaran bahwa Gedung P1 dan P2 adalah green building yang harus diwujudkan bersama.

- Menerapkan jadwal dan durasi penyiraman tanaman. Penyiraman dilakukan pagi hari untuk mengurangi kehilangan air akibat evaporasi.

- Memonitor selalu tagihan air. Apabila ada tagihan air yang melonjak dari biasanya, kemungkinan ada kebocoran.

6. Policy maker, dalam hal ini tim masterplan pembangunan P1 dan P2 harus memantau jumlah penerimaan mahasiswa setiap tahunnya. Adanya kenaikan jumlah mahasiswa akan menyebabkan kenaikan konsumsi air, yang memungkinkan tidak tercapainya penghematan penggunaan sesuai perencanaan. 


\section{DAFTAR REFERENSI}

Greenship untuk Gedung Baru. (2012). Ringkasan Kriteria dan Tolok Ukur. GBCI. Joga, Nirwono. (2011). RTH 30\%! Resolusi (Kota) Hijau. Gramedia Pustaka Utama.

Peraturan Gubernur Provinsi Daerah Khusus Ibukota Jakarta Nomor 122 Tahun 2005 Tentang Pengelolaan Air Limbah Domestik di Provinsi Daerah Khusus lbukota Jakarta.

Wijaya, Purnomo Putra. (2013). Optimasi Pencahayaan dan Penghawaan Pada Gedung Universitas Kristen Petra (P1\&P2). (Tesis No: 01000178/MTS/2012). Unpublished undergraduate thesis, Universitas Kristen Petra, Surabaya.

Wilcut, Eddie and Fry, Elliot. Air Conditioning Condensate Calculator. Retrieved October 7, 2014, from http://www.buildinggreen.com/calc/calc condensate.cfm. 